\title{
Reactive Arthritis Update: Spotlight on New and Rare Infectious Agents Implicated as Pathogens
}

\author{
Henning Zeidler ${ }^{1}$ (D) $\cdot$ Alan P. Hudson ${ }^{2}$ \\ Accepted: 21 April 2021 / Published online: 1 July 2021 \\ (C) Springer Science+Business Media, LLC, part of Springer Nature 2021
}

\begin{abstract}
Purpose of Review This article presents a comprehensive narrative review of reactive arthritis (ReA) with focus on articles published between 2018 and 2020. We discuss the entire spectrum of microbial agents known to be the main causative agents of ReA, those reported to be rare infective agents, and those reported to be new candidates causing the disease. The discussion is set within the context of changing disease terminology, definition, and classification over time. Further, we include reports that present at least a hint of effective antimicrobial therapy for ReA as documented in case reports or in double-blind controlled studies. Additional information is included on microbial products detected in the joint, as well as on the positivity of HLA-B27. Recent Findings Recent reports of ReA cover several rare causative microorganism such as Neisseria meningitides, Clostridium difficile, Escherichia coli, Hafnia alvei, Blastocytosis, Giardia lamblia, Cryptosporidium, Cyclospora cayetanensis, Entamoeba histolyticaldispar, Strongyloides stercoralis, $\beta$-haemolytic Streptococci, Mycobacterium tuberculosis, Mycoplasma pneumoniae, Mycobacterium bovis bacillus Calmette-Guerin, and Rickettsia rickettsii. The most prominent new infectious agents implicated as causative in ReA are Staphylococcus lugdunensis, placenta- and umbilical cord-derived Wharton's jelly, Rothia mucilaginosa, and most importantly the SARS-CoV-2 virus.

Summary In view of the increasingly large spectrum of causative agents, diagnostic consideration for the disease must include the entire panel of post-infectious arthritides termed ReA. Diagnostic procedures cannot be restricted to the well-known HLAB27-associated group of ReA, but must also cover the large number of rare forms of arthritis following infections and vaccinations, as well as those elicited by the newly identified members of the ReA group summarized herein. Inclusion of these newly identified etiologic agents must necessitate increased research into the pathogenic mechanisms variously involved, which will engender important insights for treatment and management of ReA.
\end{abstract}

Keywords Reactive arthritis · HLA-B27 · COVID-19 virus · Vaccination · Antimicrobial therapy

\section{Introduction}

The association between microbes and joints has attracted medical interest for decades and more, and that association remains a complex issue. The World Health Organization, in association with the Arthritis and Rheumatism Research

This article is part of the Topical Collection on Reactive Arthritis

Henning Zeidler

zeidler.henning@mh-hannover.de

1 Division of Clinical Immunology and Rheumatology, Hannover Medical School, Carl-Neuberg-Straße 1, 30625 Hannover, Germany

2 Department of Biochemistry, Microbiology, and Immunology, Wayne State University School of Medicine, Detroit, MI, USA
Council, classified the relationship between joints and infection into the following four groups [1]:

Group I: This group includes septic or infectious arthritis with the causative organism identified in joints secondary to an infection elsewhere in the body.

Group II: This group comprises post-infectious arthritis with bacterial antigens being detected in the joint.

Group III: This group includes reactive arthritis (ReA), with the infection originating in the urogenital or gastrointestinal system causing inflammatory joint disease; however, the microbes are usually not detected in the joint.

Group IV: This group consists of inflammatory arthritis triggered by microbes, where neither the organism nor 
its product or specific antigen is established in the joint.

The term ReA was introduced by Ahvonen and colleagues [2] to describe acute arthritis triggered by an extra-articular bacterial infection, often in the gastrointestinal or urogenital tract, and in which the causative organism cannot be cultured from synovial specimens. After discovery of the association between HLA-B27 and ReA [3], the term "HLA-B27 associated reactive arthritides" became common, preferentially following infections with Enterobacteria and Chlamydia. The disease was classified as a subgroup within the family of spondyloarthritis, also termed reactive spondyloarthritis [4]. However, several other arthritides fulfil the original definition, which has led to the suggestion that ReA can be divided into a B27associated and non- associated form [5]. The statement that arthritides developing after a distant infection are called reactive or post-infectious [6] is contrary to the proposal that they also should be called ReA [5].

Over time it has become evident that patients with typical ReA have microbial antigenic material, bacterial DNA and RNA and even metabolically active, persistent microbes in the synovial fluid or synovial tissue of affected joints [c.f. [7-9]]. Thus, the differentiation between post-infectious arthritis and ReA has been blurred and the diagnosis is made largely on the basis of clinical findings, medical history, and the direct and/or indirect detection of a pathogen. An option to overcome the pathogenic overlap between reactive and post-infectious in terminology might be to postulate two types of ReA: (a) "infection reactive" arthritis, characterized by the intra-articular persistence of viable, metabolic active though non-cultivable bacteria, such as shown for Chlamydia, and (b) "infection triggered reactive arthritis" [7]. In the latter, bacterial antigens derived from viable bacteria elsewhere in the body are disseminated to the joints, causing an immune-mediated arthritis. Generally, differentiation between post-infectious arthritis and ReA seems no longer terribly relevant. We therefore suggest that the use of the term "ReA" is preferable overall, as the clinical features are now established, even though no universal agreement on classification and diagnostic criteria currently exists [8].

With these indicated basic considerations related to changing disease terminology, definition, and classification over time in mind, we present a comprehensive review, with a focus on articles published between 2018 and 2020. An update is given for the microorganisms established as the main causatives of ReA, those identified as rare infective agents, and those indicated as new candidates causing ReA. Even given the diverse terminological and classification discussion summarized, we include in this review the full spectrum of infectious agents published under the term ReA.

\section{Well-Established Primary Causative Agents of Reactive Arthritis}

Reactive arthritis usually follows gastrointestinal infections by organisms from the genera Yersinia, Salmonella, Campylobacter, and Shigella, which most commonly follow dysenteric outbreaks. Alternatively, ReA often follows urogenital infection with Chlamydia trachomatis (Table 1). Asymptomatic triggering infections are reported in as many as $36 \%$ of ReA cases elicited by chlamydial, and $26 \%$ of cases elicited by enteric infection [c.f. 10]. The respiratory microorganism Chlamydophila (Chlamydia) pneumoniae, a common cause of bacterial infections worldwide, is now also well accepted as causative agent of ReA; however, ReA caused by this pathogen is less frequent than that caused by $C$. trachomatis [13]. Most patients infected with $C$. pneumoniae are asymptomatic, and the course of respiratory illness is usually relatively mild [14]. The identification of bacteria or bacterial products in the joint differs among the individual triggering agents, although thorough investigation has not always done in every instance (Table 1).

Decreasing incidence of ReA has been reported in developed countries [15]. In contrast, a recent two-centre French retrospective study reported that the frequency of ReA in patients hospitalized in Rheumatology departments did not change between 2002 and 2012 compared with the period 1986-1996 [16••]. For both cohorts, diagnosis in the majority of cases was based on clinical characteristics alone, as microorganism could not be identified by culture or PCR in synovial fluid, or by serology. Microbes were only detected in about half the patients, with a significant decrease in the number of Chlamydia trachomatis infections between the two cohorts. The trigger for infection was predominantly urogenital and gastrointestinal infection, with similar distribution of the two in both cohorts. However, some "atypical" triggers, such as Escherichia coli, Mycoplasma, Streptococcus pyogenes, Mycobacterium bovis after bacillus Calmette-Guérin treatment, and Strongyloides stercoralis, were found in the 2002-2012 cohort but not in the 1986-1996 cohort. Monocentric evaluation of 67 patients diagnosed with ReA at the Centre Hospitalier Régionale et Universitaire, Besancon, France, also reports Ureaplasma urealyticum $(n=5)$ and Neisseriae gonorrhoeae $(n=4)$ as causative agents [17].

Hayes and colleagues performed a study to characterize perspectives of 548 members of the Canadian Rheumatology Association on evolving trends of the disease [18•*]. Common investigations in ReA included inflammatory markers, HLAB27, Chlamydia and gonorrhoea testing, stool cultures, synovial fluid analyses, and SI joint imaging. Nearly half of respondents believed that the incidence of ReA is declining and that causes of ReA may be changing. Rheumatologists reported that most of the ReA cases in their practices were caused by an unknown 
Table 1 Bacterial species/groups known to be primary causes of HLA-B27 positive ReA, and identification of bacteria and bacterial products in the joint by various methods [modified from 10-12]

\begin{tabular}{|c|c|c|}
\hline Entry site & Bacteria & Bacterial products \\
\hline Urogenital tract & Chlamydia trachomatis & $\begin{array}{l}\text { Antigens, DNA, RNA, short-lived primary ribosomal RNA } \\
\text { transcripts (viability), aberrant organism by electron microscopy }\end{array}$ \\
\hline $\begin{array}{l}\text { Gastrointestinal } \\
\text { tract }\end{array}$ & $\begin{array}{l}\text { Yersinia enterocolitica } \mathrm{O3}, \mathrm{O8} \text {, and } \mathrm{O9} \\
\text { Y. pseudotuberculosis } \\
\text { Salmonella enterica } \\
\text { serovars Typhimurium enteritidis, } \\
\text { Paratyphi B and C, and others } \\
\text { Shigella flexneri, S. sonnei and S. dysenteriae } \\
\text { Campylobacter jejuni }\end{array}$ & $\begin{array}{l}\text { Antigens, RNA, DNA } \\
\text { Antigens, RNA } \\
\text { Antigens, DNA }\end{array}$ \\
\hline $\begin{array}{l}\text { Respiratory } \\
\text { tract }\end{array}$ & Chlamydia pneumoniae & Antigens, DNA, RNA \\
\hline
\end{tabular}

organism, were sexually transmitted, or followed gastrointestinal infection. Thus, there may be a need to include investigations for rare and new infective agents eliciting ReA (see below). Recent studies regarding the frequency of Chlamydia-induced ReA were reviewed, with a focus on the question of whether the entity is in fact disappearing, or whether it is simply being underdiagnosed or underreported [19••]. Epidemiological reports indicate diversity in the frequency of Chlamydia-associated ReA in various parts of the world, with evidence of declining incidence in some regions. Moreover, no epidemiologic information is available for Chlamydia pneumoniae-associated ReA, a causative entity of chlamydial infection described in case studies simply as "less frequent" [c.f. 19••].

A review of ReA following Chlamydia infection in competitive sports reported two clinical cases and provides recommendations for their clinical management [20]. Both patients, football players, presented due to an atraumatic and pain-free swelling of the knee joint. Targeted sexual history and urogenital investigation for $C$. trachomatis by PCR in urethral swabs was essential for the diagnosis. Urinary PCR can also be used for the rapid diagnosis of ReA associated with $C$. trachomatis, as recently shown in a study investigating an Indian population [21•]. C. trachomatis DNA was detected from urinary samples by PCR in 24 (36\%) of 65 ReA patients. PCR was negative in the patients with other inflammatory, arthritis as well as in a normal healthy control group.

\section{Rare Infectious Agents Implicated in the Causation of Reactive Arthritis}

Many other infectious agents have been reported to cause nonHLA-B27-associated arthritis labelled as ReA. The number has increased over the years, with considerable diversity in designation and classification, e.g. "new" candidates of arthritogenic agents [11], probable or potential agents [10], atypical causes of
ReA and variants of ReA [22], arthritis not associated with HLA-B27 [1], and possible causative agents [23]. The most recent update on ReA classified the arthritogenic agents associated with the development of the disease according to enteric infections (including amoebae-Cryptosporidium, Giardia lamblia - and the helminth Strongyloides spp.), urogenital infections, respiratory infections, and miscellaneous infections (including Human immunodeficiency virus (HIV) Parvovirus B19, Borrelia burgdorferi, Calmette-Guerin Bacillus, and Chikungunya virus) [24••]. Table 2 summarize the spectrum of infectious agents currently being referred to as initiating ReA, including information on the microbial products detected in the joint and regarding HLA-B27 positivity. The principal references documenting the additional information listed are summarized in a supplement to Table 2.

We deleted viral infections with Chikungunya virus and Parvovirus from the list of causative agents, since their clinical manifestations are heterogeneous and thus simulate different rheumatic conditions (for references see supplement to Table 2). The role of HIV infection in the causation of ReA remains unclear, i.e. whether it can cause the disease by itself or only in the context of concomitant infections typically causing ReA (for references see supplement to Table 2). Additional issues with possible HIV-related ReA include an apparent overlap of the features of reactive and psoriatic arthritis in some studies, as well as new ReA having been reported to emerge upon commencement of combination anti-retroviral therapy as a manifestation of immune reconstitution inflammatory syndrome [c.f. 26]. Other microorganisms, such as Bacillus cereus, Helicobacter cinaedi, Lactobacillus, and Streptococcus salivarius, listed in earlier reviews were not carried over here because case reports of unequivocal ReA are not identified in PubMed. On the other hand, extremely rare infectious agents, such as Cyclospora cayetanensis, Entamoeba hartmanni, Vibrio parahaemolyticus, Orientia tsutsugamushi, and Rickettsia conorii, were identified as causative agents for ReA in case reports and therefore are included as an update to the list 
Table 2 Rare infectious agents implicated to cause ReA [modified from 11, 24, 25] (see supplement for additional references reporting microbial products in the joint and HLA-B27 positivity)

\begin{tabular}{|c|c|c|c|}
\hline Entry site & Microbial agents & Microbial products in the joint & HLA-B 27 positive \\
\hline \multirow[t]{5}{*}{ Urogenital tract } & Gardnerella vaginalis & ND & Positive \\
\hline & Human immunodeficiency virus & Virus isolated in one patient & Positive in Caucasians \\
\hline & Mycoplasma genitalium/hominis/orale & DNA, coinfections & Single case \\
\hline & Neisseria gonorrhoea* & DNA & No \\
\hline & Ureaplasma urealyticum & DNA, coinfections & No \\
\hline \multirow[t]{10}{*}{ Gastrointestinal tract } & Blastocytosis* & ND & Single case \\
\hline & Clostridium difficile & ND & Yes \\
\hline & Cyclospora cayetanensis* & ND & No \\
\hline & Echerichia coli & ND & Some cases \\
\hline & Hafnia alvei & ND & No \\
\hline & Helicobacter pylori & ND & Yes \\
\hline & Microsporidia & Antigens, DNA, culture positive & Single case \\
\hline & Strongyloides stercoralis* & Larva and antigen found in SM (one case) & Single case \\
\hline & Tropheryma whippelii** & DNA, rRNA, culture positive & Some cases \\
\hline & Vibrio parahaemolyticus & ND & ND \\
\hline \multirow[t]{4}{*}{ Amoebae } & Cryptosporidium & ND & No \\
\hline & Entamoeba histolytica* & Culture positive in one case & No \\
\hline & Entamoeba hartmanni* & $\mathrm{ND}$ & Single case \\
\hline & Giardia lamblia* & ND & Some cases \\
\hline \multirow[t]{4}{*}{ Respiratory tract } & $\beta$-haemolytic Streptococci & ND & Some cases \\
\hline & Mycobacterium tuberculosis* & $65 \mathrm{kDa}$ mycobacterial heat shock protein reactive T-cells & Some cases \\
\hline & Mycoplasma pneumoniae & $\mathrm{ND}$ & Some cases \\
\hline & Neisseria meningitidis & Immune complexes & Single case \\
\hline \multirow[t]{15}{*}{ Other (skin, soft tissue) } & Bartonella henselae & $\mathrm{ND}$ & No \\
\hline & Borrelia burgdorferi** & DNA & No \\
\hline & Brucella abortus/mellitensis & Culture negative by definition & No \\
\hline & Calmette-Guerin Bacillus & Mycobacteri bovis culture positive in one case & Yes \\
\hline & Coxiella burnetii & ND & ND \\
\hline & Leptospira & ND & ND \\
\hline & Orientia tsutsugamushi* & ND & ND \\
\hline & Propionibacterium acnes & Culture positive & Single case \\
\hline & Pseudomonas aeruginosa & DNA & No \\
\hline & Rickettsia conorii* & Immune complexes & No \\
\hline & Rickettsia rickettsii* & Culture negative (single case) & Single case \\
\hline & Staphylococcus aureus & ND & Some cases \\
\hline & Staphylococcus epidermidis & ND & Single case \\
\hline & Staphylococcus haemolyticus & ND & Single case \\
\hline & Staphylococcus lugdunensis & ND & ND \\
\hline \multirow[t]{5}{*}{ Vaccination } & Hepatitis B & ND & Two cases \\
\hline & Influenza & ND & Single case \\
\hline & Measles plus mumps & ND & ND \\
\hline & Tetanus & ND & Positive \\
\hline & Typhoid & ND & No \\
\hline
\end{tabular}

*Effective antimicrobial therapy for ReA documented in case reports

**Effective antimicrobial therapy for ReA documented in double-blind controlled studies 
(Table 2; for references see supplement to Table 2). Finally, causative agents sensitive to antimicrobial therapy with efficacy to treat $\mathrm{ReA}$ are marked in Table 2 (for references see supplement to Table 2).

The list clearly shows the overlap between reactive and post-infectious arthritis, in that different arthritides with and without detection of microbial products in the joint are included together under the label ReA. In addition to bacteria, viruses, protozoa, amoeba, helminths, and vaccinations are listed as triggers for ReA. Regardless of the controversy relating to differentiation between the two forms of arthritis, a distinction is rarely made in clinical practice or in publications in cases of clinical similarities of joint manifestation. Moreover, infections with Tropheryma whippelii, Borrelia burgdorferi, Neisseria gonorrhoea, and some protozoa have therapeutic implications due to antimicrobial therapy. Recent publications thus have extended our knowledge about rare causative agents of $\operatorname{ReA}$.

\section{Urogenital Infections}

A recent case report from Japan describes chronic ReA in a patient associated with chronic asymptomatic prostatitis caused by Neisseria meningitidis [27]. The patient had several features of ReA, including positive HLA-B27, asymmetric chronic arthritis in the lower extremities, enthesitis, and persistent urinary tract infection. Contrast-enhanced CT scans demonstrated enhanced lesions in the peripheral zone of the prostate. Culture of urine taken after prostate massage revealed Neisseria meningitidis. The critical lesson from this case is that in a patient with suspected $\operatorname{ReA}$, it is important to look for possible unusual sites of infection, even if the infection is asymptomatic.

\section{Gastrointestinal Infections}

Clostridium difficile colitis is less often recognized as a cause of ReA. A recent report described a 58-year-old HLA-B27 positive woman with complaints of non-bloody watery diarrhoea, abdominal pain for the past 1 week, and right knee pain starting 1 day prior [28]. The patient had recently used antibiotics for a respiratory tract infection and was found to be positive for Clostridium difficile toxin in stool. ReA secondary to Clostridium difficile colitis was diagnosed, treatment with oral vancomycin and an anti-inflammatory was initiated, and the patient had complete resolution of symptoms. This case illustrates the importance to test for Clostridium difficile toxin in undifferentiated arthritis patients under the appropriate circumstances. It may be useful to remember the diagnostic criteria for ReA associated with Clostridium difficile infection proposed by Birnbaum et al. which include the following: (i) evidence of aseptic synovitis (confirmed by culture) developing during or immediately after colitis, (ii) presence of toxins produced by Clostridium difficile in stool samples, and (iii) absence of other causes of colitis and arthritis [29].

Using a prospective research design, Tuompo et al. at the University of Helsinki and Helsinki University Hospital, Finland, evaluated the association between acquisition of diarrhoeagenic Escherichia coli (DeC) and development of ReA and other reactive musculoskeletal symptoms among international travellers [30•]. ReA was defined as development of synovitis (swelling accompanied by pain and/or painful movement) in a previously asymptomatic joint within 2 months after gastrointestinal symptoms. Of 151 patients with only DeC infection, and excluding other pathogens, four $(2.6 \%)$ had ReA, two $(1.3 \%)$ reactive tendinitis, and three $(2.0 \%)$ reactive arthralgia. ReA was mostly mild, and all patients with ReA were negative for HLA-B27. Pathogens involved were identified only because of participation in this study; travellers mostly do not seek medical care for mild travellers' diarrhoea symptoms. Antibiotic treatment of travellers' diarrhoea did not prevent development of musculoskeletal symptoms.

With regard to rheumatic manifestations following E. coli infection, it is important to remember the recent report of ReA from post-urogenital E.coli infection [31]. In this report, a 54year-old Bangladeshi woman presented with the clinical picture of ReA following an episode of an E. coli positive urinary tract infection 2 weeks prior to acute right hip joint arthritis onset. Laboratory testing revealed that she was HLA-B27 negative but strongly positive for rheumatoid factor as well as anti-CCP antibody. Symptoms improved significantly within 5 days and with treatment using intramuscular steroid injection in addition to analgesia (NSAIDs and paracetamol). However, further follow-up of this patient is required to assess if she is at risk of developing overt clinical features of rheumatoid arthritis.

The diagnosis of post-enteric ReA is challenging given the diversity of enteric pathogens. Stool culture and serological tests may be negative at the time of diagnosis, making it impossible to identify the causal agent. Moreover, rare enteric microorganism may infrequently cause ReA. For only the second time, ReA associated with Hafnia alvei has been reported recently [32]. A 50-year-old man with persistent inflammatory low back pain, asymmetric oligoarthritis, and a clinical history positive for diarrhoea in the previous 3 months was diagnosed with presumptive ReA after careful exclusion of other inflammatory bowel diseases. Persistence of symptoms after treatment with a non-steroidal anti-inflammatory drug prompted a second look at the colon. Biopsy collected from the terminal ileum was cultured, and surprisingly, colonies of Hafnia alvei, a rod-shaped Enterobacteriaceae, were detected. Treatment with ciprofloxacin led to rapid resolution of symptoms. Although enterocolitis from Hafnia alvei has been reported only rarely, the culture of intestinal specimens 
might be recommended in the work-up of patients with suspected post-enteritic ReA.

Blastocystis is an enteric parasite that is endemic particularly in developing countries, and it has only rarely been encountered as the causative organism of ReA. A recent case report from Qatar presented the first case of ReA with urticaria caused by Blastocystis [33॰]. The 18-year-old female patient presented after 2 weeks of diarrhoeal illness with a 3-day history of urticarial skin rash followed by arthritis affecting knees, elbows, shoulders, and ankles in addition to small joints of the right hand, and tenosynovitis of both the Achilles tendons. She was found to have Blastocystis by the stool microscopy and received metronidazole with a short course of NSAIDS and steroids leading to complete resolution of her skin and joint symptoms. Thus, especially in endemic areas, it is important to consider organisms other than the classical ones as a trigger for ReA. A recent study of patients having unexplained rheumatic pain attending the rheumatology and rehabilitation outpatient clinic in Suez Canal University Hospital reported the frequency of intestinal parasitic infection fulfilling the criteria for parasitic rheumatism, which is often published under the term ReA [34]. The results of examination of stool samples showed that 50 of 107 patients with unexplained rheumatic pain had a parasitic infection. Cryptosporidium infection was the most common (48\%), followed by Cyclospora cayetanensis (32\%), Giardia lamblia (24\%), Blastocystis hominis (20\%), and Entamoeba histolytica (8\%). Parasitic rheumatism was diagnosed in 16 of the 50 patients (32\%) most commonly due to Gardia infection, followed by Cryptosporidium, Cyclospora cayetanensis, Entamoeba histolytica/dispar, and Strongyloides stercoralis.

\section{Respiratory Infections}

Poststreptococcal ReA (PSRA) is associated with prior group A, $\beta$-hemolytic streptococcal infection. Distinguishing PSRA from acute rheumatic fever (ARF) can be challenging. For that reason, Chun and Kingsbury reviewed the diagnostic criteria for PSRA, the pertinent features of the 2015 ARF diagnostic guideline from the American Heart Association, and the major characteristics that differentiate PSRA from ARF [35].

Tuberculosis is an important public health problem and is a re-emerging disease, particularly in underdeveloped countries. Thus, several cases of ReA induced by active extra-articular tuberculosis (Poncet disease) have been reported in recent years. Sood et al. in New Delhi, India, described 7 patients who presented primarily with polyarthritis and fever and who developed pulmonary, pleural, or nodal tuberculosis later in the course of disease [36]. Polyarthritis resolved and did not recur in all the patients after the institution of antitubercular treatment comprised of isoniazid, rifampicin, pyrazinamide, and ethambutol for the first 2 months, followed by isoniazid and rifampicin for next 4-5 months. Another case report, also from India, presented 5 patients with diagnosis of Poncet's disease and examined the performance of diagnostic criteria suggested by Sharma et al. [37, 38•]. All the patients with Poncet's disease had a definite diagnosis as per these criteria, illustrating their utility in routine clinical practise. The majority $(4 / 5)$ of the patients were subsequently diagnosed and responded to anti-tuberculous therapy. In the other patient, a diagnosis of atypical seropositive rheumatoid arthritis or pseudo Poncet's disease was established on follow-up. Calado et al. recently reported cutaneous tuberculosis, a rare extrapulmonary manifestation of tuberculosis, associated with reactive Poncet arthritis which showed improvement of the clinical and skin condition after appropriate treatment [39]. Lastly, a case report from Japan described a patient with Poncet disease who was successfully treated with a TNF inhibitor after sufficient antitubercular treatment [40].

The association between ReA and acute Mycoplasma pneumoniae infection has been reported sporadically, mainly in children [41]. A recent case report described a 30-year-old Greek patient who was HLA-B27 positive and who presented with acute Mycoplasma pneumoniae infection complicated by ReA and asymmetric proximal myopathy; this had progressed to chronic spondyloarthritis [42]. This previously healthy man presented to an emergency department with fever, sore throat, progressively worsening bilateral lower limb weakness, and asymmetric oligoarthritis. Diagnosis was based on a positive polymerase chain reaction test for Mycoplasma pneumoniae using template prepared from blood and cerebrospinal fluid, and magnetic resonance imaging findings that suggested sacroiliitis. The infection was successfully treated with a 14day course of doxycycline, and the patient was discharged without neurological symptoms. The arthritis was treated with naproxen and corticosteroids; it improved initially but later progressed to chronic spondyloarthritis. This case exemplifies the fact that extrapulmonary manifestations of Mycoplasma pneumoniae can occur even in the complete absence of respiratory symptoms. Diagnosis of unusual complications relating to such infections, including ReA, requires a high level of clinical suspicion and extensive investigation. Diagnosis of Mycoplasma pneumoniae infections is challenging. Current diagnostic modalities include various direct PCR assays, serology, and culture [43]. The gold standard for serological diagnosis is a fourfold change in antibody titres over time; IgM antibody titres rise earlier than do IgG antibodies.

\section{Other Infections, Including Skin and Soft Tissue}

ReA induced by intravesicular injection of the attenuated Mycobacterium bovis bacillus Calmette-Guerin (BCG) is a rare but well-known complication of non-muscle-invasive bladder cancer therapy. Cheung et al. published a unique case describing the management of repeated BCG induction which followed BCG-induced Reiter syndrome in the primary 
induction series; this occurred after a 16-year disease-free interval [44]. Following the third dose, the patient developed ReA with worsening dysuria, fever, diffuse enthesitis, episcleritis, and arthritis of both knees, both ankles, left wrist, and left temporomandibular joint. The fourth instillation of BCG was delayed by 2 weeks, and the ReA was managed with steroid injections and oral non-steroidal anti-inflammatory drugs. The decision was made to give the final induction doses as scheduled. After completing his induction BCG, the rheumatologist took a more active approach to managing his arthritis, and the patient was started on oral sulfasalazine (1500 mg twice daily) and prednisone (7.5 mg daily). On this regimen, his symptoms completely resolved. Although more research is required, this case demonstrates that repeat induction is an option in the appropriate patient setting, assuming risk and benefit assessment, shared decision-making, and active rheumatologist involvement. Another recent case report of an HLA-B27 positive patient with ReA following intravesical BCG instillation illustrates that symptoms of arthritis resolved completely after a 1-year progressively reduced corticosteroid treatment [45]. Ultrasonographic findings of synovitis in both wrists, together with wrist flexor tenosynovitis, wrist extensor tenosynovitis, and also enthesitis of the flexor carpi radialis tendon, supported the diagnosis of ReA induced by intravesical BCG therapy for bladder cancer in a Japanese patient who was HLA-B27 negative but B35 positive [46]. Slouma et al. report as $\operatorname{ReA}$ the case of a 24-year-old Tunisian man, HLA-B27 positive, developing after the ninth BCG instillation inflammatory back pain and with evolution to an axial spondyloarthritis diagnosed 9 years later [47]. This would be the first case report presuming BCG induced axial spondyloarthritis, although one cannot exclude other intermittent asymptomatic infections as causatives for the late development of spondyloarthritis.

Several tick-borne rickettsial organisms can trigger ReA (Table 2). Redford et al. reported a case in which Rickettsia rickettsii, acquired on a camping trip, precipitated a flare of peripheral arthritis and episcleritis in a 45-year-old female; this patient had a 19-year history HLA-B27 positive spondyloarthritis which was well controlled for 4 years on anti-tumour necrosis factor-alpha (anti-TNF) therapy (certolizumab pegol $400 \mathrm{mg}$ subcutaneously every 4 weeks) [48]. The patient had a 14-day course of doxycycline, which led to complete resolution of symptoms and resumption of her certolizumab therapy.

\section{Evidence for Rare Infectious Agents Implicated in the Causation of Reactive Arthritis}

Evidence for the causation of the organisms listed in Table 2 in ReA is extremely diverse, varying between single case reports, e.g. for Hafnia alvei [32], and comprehensive literature reviews, e.g. for Clostridium difficile [49]. Diagnosis is based on the clinical history of an arthritis following an extraarticular infection, verified by testing for the causative agent (positive culture at the site of infection and/or serum antibacterial antibodies) but also includes arthritis following vaccination. Diagnostic criteria from the Third International Workshop on Reactive Arthritis and the criteria published by Pacheco-Tena et al. both mention only clinical diarrhoea or urethritis as the preceding infections [50, 51]. Thus, respiratory infections and vaccination are not included in the available criteria. Pacheco-Tena et al. add to their diagnostic criteria bacterial identification by peripheral blood or synovial lymphocyte proliferation, and/or synovial fluid or tissue immunofluorescence bacterial antigens or DNA or RNA detection, but these investigations are only rarely performed for the microbial agents listed in Table 2 [51]. Siala et al. conducted studies to detect bacterial DNA present in synovial tissue and synovial fluid, respectively, of Tunisian patients with ReA and other arthritides using broad-range bacterial PCR; the assay targeted a 1400-bp fragment from the 16S rRNA gene followed by cloning and sequencing the entire $16 \mathrm{~S}$ rDNA from a wide variety of bacterial species $[52,53]$. Characterization of the DNA sequences in all patients revealed a wide spectrum of commensal and environmental organisms not known to date to be present in human infections, not known to be present in inflamed joints of arthritis patients, and not known to trigger ReA. Therefore, the results of these and earlier studies with highly sensitive broad-range PCR [c.f. [53] indicate that arthritic joints are not sterile, and that the role of microorganisms triggering $\mathrm{ReA}$ requires further investigation.

A major problem exists in relation to the inclusion of arthritides induced by, e.g. Borrelia burgdorferi, Neisseria gonorrhoeae, and Tropheryma whippelii. The infection and rheumatic manifestations are treatable with antimicrobial medication despite negative culture results in the joint. Unexplained seronegative peripheral arthritis should have culture and/or PCR tests for these infectious agents whenever possible, including using the appropriate sample such as blood, stool, urine, skin biopsy, duodenal biopsy, saliva, joint fluid, and/or synovial biopsy [c.f 34, 54-57].. Although the arthritides indicated above were formerly termed ReA and are included within the spectrum of ReA in reviews, it is important to mark the therapeutic difference given in clinical practice and the overlap to infectious arthritis.

Thus, the boundary between septic arthritis and ReA is characterized neither by the fact that the instigating bacteria are present in the joint or distant from the joint, nor by the fact that these organisms may or may not be intracellular; rather, that boundary may be characterized by the replicative or nonreplicative form of these germs. The term "septic arthritis" might define situations in which the bacteria proliferate in the joint, whereas the term "reactive arthritis" should be used 
to define situations in which inflammation is perpetuated by living, but non-replicative, bacteria [58].

\section{New Infectious Agents Implicated in the Causation of Reactive Arthritis}

ReA has been described only infrequently in association with Staphylococcus aureus, the coagulase-negative staphylococci Staphylococcus epidermidis, and Staphylococcus haemolyticus (for references see supplement to Table 2). A recent case report presented ReA in a 51-year-old male undergoing chemotherapy for pancreatic cancer who presented with joint pain and fevers. He was found to have blood culture and urine culture positive for Staphylococcus lugdunensis [59]. Transthoracic and transesophageal echocardiograms were negative for endocarditis. The likely source of Staphylococcus lugdunensis bacteremia was an indwelling catheter. Arthrocentesis from one large joint revealed culture-negative inflammatory synovitis. This case illustrates that a possible systemic manifestation of Staphylococcus lugdunensis bacteremia, in addition to the more common endocarditis, can also include ReA.

Orthobiologic injections, for example the placenta- and umbilical cord-derived Wharton's jelly, are currently being harvested and sold by companies as an off-the-shelf "stem cell" injection for conditions including back pain and osteoarthritis. For example, a 36-year-old male was injected with Wharton's jelly for low back pain, and within $24 \mathrm{~h}$ he developed fevers, chills, polyarthritis, and Achilles tendon enthesitis [60]. Infectious disease work-up was negative. Inflammatory markers were elevated, and he was positive for HLA-B27 antigen. Initial treatment included methylprednisolone and sulfasalazine. This example highlights the unknown dangers of these allogenic injections, and physicians should remain cautious about their use until further study and regulation can ensure patient safety.

Rothia mucilaginosa, also known as Stomatococcus mucilaginosus or Micrococcus pneumoniae, is a Grampositive coccus that is part of the normal microbiota of the oropharynx and upper respiratory tract and is considered a non-pathogenic bacterium in healthy individuals. In one report, a 79-year-old diabetic man who presented with a 1-month history of polyarthralgia involving the shoulder and hip joints was initially suspected of having polymyalgia rheumatica [61]. Gallium-67 scintigraphy revealed a marked uptake in tendon attachments around the shoulders and hips bilaterally, which is usually typical for polymyalgia rheumatica. Pharyngeal bacterial culture was repeated twice, with both cultures positive for Rothia mucilaginosa susceptible to ampicillin. Ampicillin treatment was initiated at a dose of $750 \mathrm{mg} /$ day for 3 months, leading to resolution of all clinical symptoms, and with no relapse over a 1-year follow-up, supporting the diagnosis of ReA. This unusual case has been interpreted to mean that an uncommon organism may cause ReA in individuals at risk for infections, such as those with diabetes, and that clinicians should avoid a misdiagnosis of seronegative rheumatic diseases, such as polymyalgia rheumatica. However, that clinical manifestation is extremely rare in ReA and in the scintigraphy typical for polymyalgia; hence, the conclusion is questionable.

With the advent of the SARS-CoV-2 pandemic, several cases of acute arthritis following this viral infection were reported and classified as ReA (Table 3) [62-69]. The first review published in October 2020 as preprint discussed whether SARS-CoV-2 can trigger ReA [70 •]. The question arises whether COVID-19 virus-associated arthritis should be classified as ReA, as we also have discussed for Chikungunya virus and Parvovirus. Nevertheless, we provide here a complete review of relevant publications through the end of 2020.

The arthritis manifests from a few days up to 21 days after infection and from COVID-19 symptom onset, respectively. Joint involvement is oligoarticular, which is typical for ReA. Enthesitis of the Achilles tendon and psoriatic lesions consistent with spondyloarthritis have also been observed $[62,66]$. Extra-articular involvement of palpable purpura of both calves was seen in one HLA-B27 positive patient [67]. HLA-B27 is otherwise negative, although this has been investigated in only one case. Synovial fluid examination with reverse transcriptase (RT)-PCR for SARS-CoV-2, investigated in two cases, was negative $[64,65]$. In one case, negative viral cultures for SARS-CoV-2 were reported [65]. Of note, the clinical significance of the synovial fluid cultures and RT- PCR results is currently unknown, and the report highlights an unmet need in relation to SARS-CoV-2 ReA diagnosis [71]. The arthritis resolved spontaneously on day 27 in one patient. In the other patients, the arthritis was managed with non-steroidal anti-inflammatory drugs and intra-articular corticosteroid injection.

Importantly, four cases of acute arthritis developed during COVID-19 admissions have been reported, all due to crystalproven flares (gout and calcium pyrophosphate disease) [72]. Therefore, during the SARS-CoV-2 pandemic, it remains essential to check every case of acute arthritis by polarized microscopy since acute illnesses, including infections, are wellestablished risk factors for gout and pseudogout flares [73].

\section{Synovial Pathogenesis}

Given an ever-widening array of organisms implicated in the etiology of ReA, the critical issue becomes: what is/are the pathogenic mechanism(s) underlying disease induction? Does one common process produce the arthritis regardless of initiating organism; does some small number of related processes exist to accomplish disease induction regardless of infecting organism, or are pathogenesis and disease induction differentially and individually specified by each such organism? 


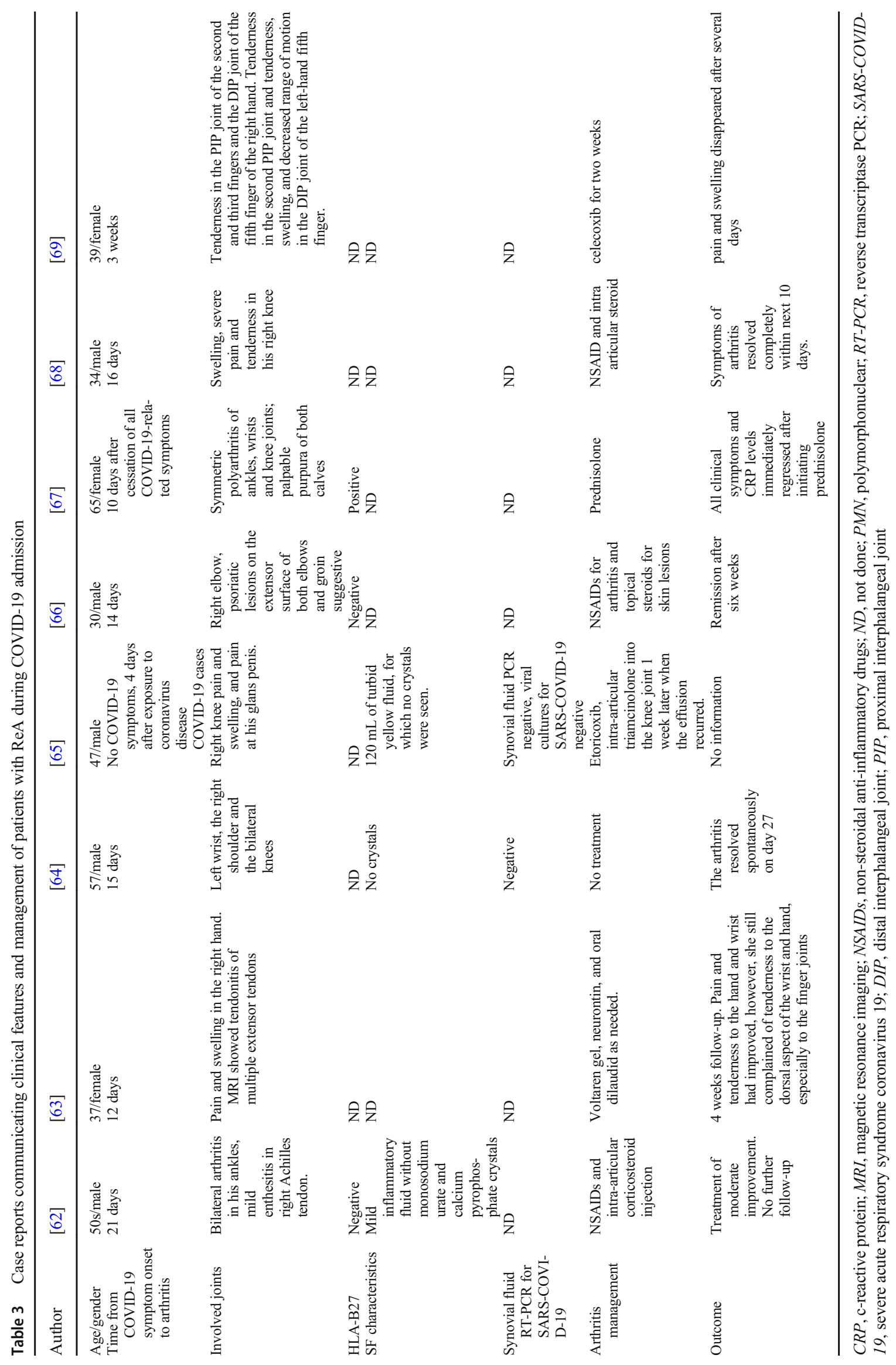


For the well-established and well-studied primary etiologic agents, including Chlamydia trachomatis and the various Gram-negative gastrointestinal pathogens, a reasonably good understanding exists concerning mechanisms of joint pathogenesis in ReA. In the case of arthritis occurring postC. trachomatis genital infection, studies have indicated that the organism is transported to the joint intact in infected monocyte/macrophages, and it establishes itself within those cells in synovial tissue, there eliciting synovial inflammation. The pathogen is in an unusual metabolic state during transport and establishment in synovial tissue, referred to as "persistence", which is characterized in part by an unusual panel of gene expression and partial antibiotic refractoriness. Destruction of Chlamydiae in monocyte/macrophages is aborted due to as yet poorly understood aspects of pathogen-host cell interaction at the molecular level [see e.g. [74-76]]. This is in contrast to infecting gastrointestinal pathogens, which do not reach the joint in a viable and intact state. Rather, studies have demonstrated that parts of the infecting organism that include "arthritogenic peptides" reach the synovium, where it is thought that they are displayed by a subset of HLA-B27 allelic products to elicit an inflammatory response; at least in part, that response may occur via molecular mimicry, thus initiating autoimmunity [74, 77]; see also below]. Several other explanations for pathogenesis have been put forward in the HLA-B27 context, including heavy chain homodimer formation and HLA-B27 misfolding. It should be noted, however, that the rate of HLA-B27 positivity in ReA patients is lower than that in patients with ankylosing spondylitis (30-50\% vs $80 \%$ or more, respectively). Thus, other mechanisms for joint inflammation and pathogenesis must exist; one of these may well relate to the overall composition and alteration of gut microbiota in some patients [74 and see below].

Further, it has been clear for many years that ReA can be one of several possible sequelae to inflammatory bowel disease (IBD). In these cases, the arthritis and other morbidities have been linked to the structure of some specific forms of lipooligosaccharides from the infecting organism which interact with the host innate immune system [e.g. 78]. Multiple levels of interactions between the host and infecting pathogen are emerging as critical to disease induction. Recent in silico studies have indicated, for example, that the $\mathrm{Na} / \mathrm{H}$ antiporter and kynureninase, among several other proteins, are important targets for such interaction; these and similar kinds of studies will provide critical guidance for researchers to design experimental systems for dissection of those detailed interactions, and for elucidation of pathogenesis mechanisms elicited by novel agents given in previous sections [79].

Other etiologic agents for ReA are not among the Gramnegative bacteria as are those discussed above, but are rather Gram-positive, the Group A Streptococci, the Staphylococci, Rothia spp., and others. Interestingly, post-Streptococcal ReA has been recognized and reported for many years, while arthritis related to these others has been reported only rarely [e.g. 80, 81]. It seems probable from several studies that ReA in this context is a function of the known and wellcharacterized pathogenic proteins produced by these bacteria. Further, and importantly, it is likely that joint pathogenesis elicited by the more recently identified bacterial and eukaryotic pathogens introduced above, such as $H$. alvei, C. difficile, and Blastocystis, will follow that same pattern [see 82, 83]. Much more research will be required to sort out details of synovial inflammation and pathogenesis by these newly identified agents. It will be of significant interest to follow details of such studies, including whether patients with ReA apparently caused by these organisms conform to relatively wellestablished patterns for disease elicited by other, classic pathogens, such as that of HLA-B27 positivity, or whether new and expanded categories of characteristics and pathogenic mechanisms will be defined.

Arthritis following respiratory infection is an interesting issue, especially with respect to whether the organisms eliciting it are, in fact, present in the joint and intact to engender disease. ReA following extra-articular tuberculosis, as mentioned above, has been reported a number of times, and it is treatable with standard antituberculosis treatment; it is not clear from most of the reports whether Mycobacterium tuberculosis or some of its components are in fact identifiable in synovial fluid or tissues. In cases of arthritis following pulmonary infection with Mycoplasma pneumoniae, nucleic acids from the organism have been identified by PCR in blood samples and, as mentioned above, from CSF, suggesting that the organism or its parts are likely to be present in the affected joint [42]. We have studied the ReA that can follow pulmonary infection with Chlamydia pneumoniae [e.g. 84]. As with studies of $C$. trachomatis-induced ReA, we identified the organism within the joint in C. pneumomiae-induced arthritis, and we found production of messengers for multiple proinflammatory mediators there as well. The organism is viable and metabolically active within the joint, as with $C$. trachomatis $[75,85]$. Thus, the mechanism(s) eliciting joint inflammation and pathogenesis in the context of $C$. pneumoniae infection is/are congruent to that/those characteristic of $C$. trachomatis at that site.

Importantly, a number of recent studies have indicated that the epidemiology of ReA has been changing. In part, this alteration in disease distribution and diagnosis results from evolving, and somewhat inconsistent, diagnostic criteria [e.g. $18,86]$. It may also result, in some cases, from a general lack of recognition of this arthritis in affected patients [19, 87]. However, in large part this change in disease distribution must result from recognition of the increasing array of etiologic agents underlying the disease, including viruses. Reports of arthritis in patients with current or previous viral infections have appeared from time to time in the literature [see 88] for discussion]. With the advent of the current viral pandemic, reports of patients with inflammatory arthritis following 
SARS-CoV-2 infection have proliferated [e.g. 62, 89, 90]. Most such reports simply describe the case of one or a few patients, and the treatments administered with outcomes, but most do not include PCR or other testing to assess presence of the virus or its parts in the synovium. Thus, determination of pathogenic mechanisms must await further research. One reasonable possibility, though, centres on the question of molecular mimicry. In one recent study of alphavirus-mediated arthritis, the authors performed an extensive in silico analysis to ask whether molecular mimicry post-viral infection could elucidate a possible autoimmune reaction to engender the arthritis; the answer provided indicated that it was indeed possible [91]. Much more study will be required to assess diseaseinducing mechanisms in post-viral contexts, as well as in situations in which other pathogens elicit inflammatory arthritis.

\section{Conclusion}

In view of the large spectrum of causative agents, it is clear that diagnostic consideration must include the entire diversity of post-infectious arthritis termed ReA. The diagnostic procedure should not be restricted to the well-known HLA-B27associated group of ReA, but must also cover the large number of more rare forms of arthritis following infections and vaccinations, as well as newly described members of the group of ReA summarized in this review. This increased array of pathogens must support increased research into the panoply of mechanisms involved in disease elicitation, and elucidation of those mechanisms will in turn inform the treatment and management of ReA in all contexts.

Supplementary Information The online version contains supplementary material available at https://doi.org/10.1007/s11926-021-01018-6.

\section{Declarations}

Conflict of Interest The authors declare no competing interests.

\section{References}

Papers of particular interest, published recently, have been highlighted as:

- Of importance

•- Of major importance

1. Mathew AJ, Ravindran V. Infections and arthritis. Best Pract Res Clin Rheumatol. 2014;28:935-59.

2. Ahvonen P, Sievers K, Aho K. Arthritis associated with Yersinia enterocolitica infection. Acta Rheumatol Scand. 1969;15(3):232 53.
3. Aho K, Ahvonen P, Lassus A, Sievers K, Tilikainen A. HL-A antigen 27 and reactive arthritis. Lancet. 1973;2(7821):157.

4. Leirisalo-Repo M, Sieper J. Chapter 5 - Reactive spondyloarthritis: epidemiology, clinical features, and treatment. In: Weisman MH, Reveille JD, van der Heijde D, editors. Ankylosing spondylitis and the spondyloarthropathies. Philadelphia: Mosby Elsevier; 2006. p. 53-64.

5. Toivanen P, Toivanen A. Two forms of reactive arthritis? Ann Rheum Dis. 1999;58:737-41.

6. Keat A. Reactive arthritis or post-infective arthritis? Best Pract Res Clin Rheumatol. 2002;16:507-22.

7. Kuipers JG, Köhler L, Zeidler H. Reactive or infectious arthritis. Ann Rheum Dis. 1999;58:661-4.

8. Hannu T, Inman R, Granfors K, Leirisalo-Repo M. Reactive arthritis or post-infectious arthritis? Best Pract Res Clin Rheumatol. 2006;20:419-33.

9. Carter JD, Hudson AP. Reactive arthritis: clinical aspects and medical management. Rheum Dis Clin N Am. 2009;35(1):21-44.

10. Colmegna I, Cuchacovich R, Espinoza LR. HLA-B27-associated reactive arthritis: pathogenetic and clinical considerations. Clin Microbiol Rev. 2004;17:348-69.

11. Sibilia J, Limbach FX. Reactive arthritis or chronic infectious arthritis? Ann Rheum Dis. 2002;61:580-7.

12. Rihl R, Klos A, Kohler L, Kuipers JG. Reactive arthritis. Best Pract Res Clin Rheumatol. 2006;20:1119-37.

13. Carter JD, Inman RD. Chlamydia-induced reactive arthritis: hidden in plain sight? Best Pract Res Clin Rheumatol. 2011;25:359-74.

14. Burillo A, Bouza EP. Chlamydophila pneumoniae. Infect Dis Clin N Am. 2010;24:61-71.

15. Kononoff A, Arstila L, Pussinen P, Kautiainen H, Elfving P, Savolainen E, et al. Incidence of inflammatory joint diseases in Finland: results from a population-based epidemiological study. Rheumatol Int. 2017;37:1693-700.

16••. Courcoul A, Brinster A, Decullier E, et al. A bicentre retrospective study of features and outcomes of patients with reactive arthritis. Joint Bone Spine. 2018;85:201-5 The French two-centre retrospective study reports that the frequency of $\operatorname{ReA}$ in patients hospitalized in rheumatology department did not change between 2002 and 2012 compared with between 1986 and 1996. This is the first study of ReA features over a large period of time of 26 years. In the majority of cases, the diagnosis is based on clinical characteristics alone, as microorganism could not be identified by culture or PCR in synovial fluid or by serology. The trigger for infection was predominantly urogenital and gastrointestinal, with similar distribution in both cohorts. However, some "atypical" triggers, such as Escherichia coli, Mycoplasma, Streptococcus pyogenes, Mycobacterium bovis after bacillus Calmette-Guérin immunotherapy, and Strongyloides stercoralis, were found in the 2002-2012 cohort and not in the 1986-1996 cohort.

17. Brinster A, Guillot X, Prati C, Wendling D. Evolution over thirty years of the profile of inpatients with reactive arthritis in a tertiary rheumatology unit. Reumatol Clin. 2018;14:36-9.

18••. Hayes KM, RJP H, Turk MA, Pope JE. Evolving patterns of reactive arthritis. Clin Rheumatol. 2019;38:2083-8 Members $(\boldsymbol{n}=\mathbf{5 4 8})$ of the Canadian Rheumatology Association were surveyed with questions covering their demographic information, subspecialty, level of experience, practice setting and opinions on prevalence, treatment, and causes of ReA. Although the response rate was only $18 \%$ limiting the generalizability, there were however no differences between respondents with respect to type of practice and experience. ReA may be decreasing in frequency and severity (less than full triad of symptoms and less chronic ReA) in Canada. Changes could be due to less food-borne illness, cleaner water, more rapid treatment of sexually transmitted infections, or mutations of common infectious 
causes of $\operatorname{ReA}$ to strains with less chance of producing an immune response (less arthritogenic) but this is speculative.

19••. Zeidler H, Hudson AP. Chlamydia-induced reactive arthritis: disappearing entity or lack of research? Curr Rheumatol Rep. 2019;21:63 The review highlights that epidemiological studies have indicated a diversity of the incidence and frequency of Chlamydia-associated ReA in different parts of the world, with evidence of declining incidence in some regions. The overall number of published primary research reports and reviews focused on Chlamydia-induced ReA has declined significantly in recent years raising the question whether the entity is in fact disappearing or whether it is simply being underdiagnosed or underreported.

20. Klingebiel S, Rieger H, Gosheger G, Theil JC, Rickert C, Schneider $\mathrm{KN}$. Postinfectious reactive arthritis after Chlamydia infection in competitive sports: Clinical management and current literature review. (in German) Orthopäde. 2020. German. doi: https://doi.org/ 10.1007/s00132-020-03935-3

21 •. Sharma M, Sharma S, Sharma A, Sharma K. Chlamydia trachomatis associated reactive arthritis: a urinary PCR based study. Indian Dermatol Online J. 2020;11:21-4 This is the first study showing that urinary PCR can also be used for the rapid diagnosis of $\operatorname{ReA}$ associated with $C$. trachomatis. PCR using specific primers for $C$. trachomatis was carried out from urine samples of 65 patients with ReA, 20 of other inflammatory arthritis, and 20 healthy controls. PCR was positive in $\mathbf{2 4}$ $(36 \%)$ of the ReA patients and was negative in all patients of other inflammatory arthritis as well as in normal healthy control group.

22. Morris D, Inman RD. Reactive arthritis: developments and challenges in diagnosis and treatment. Curr Rheumatol Rep. 2012;14: 390-4.

23. Pennisi M, Perdue J, Roulston T, Nicholas J, Schmidt E, Rolfs J. An overview of reactive arthritis. JAAPA. 2019;32:25-8.

24••. García-Kutzbach A, Chacón-Súchite J, García-Ferrer H, Iraheta I. Reactive arthritis: update 2018. Clin Rheumatol. 2018;37:869-74 The review shows a complete list of the arthritogenic agents which are reported to be associated with the development of $\operatorname{ReA}$. The authors believe that the prevalence of $\operatorname{ReA}$ has been underestimated because of the multiple clinical manifestations, different degrees of disease activity, and geographical and genetical differences that make the diagnosis many times more difficult, although the disease may be as common as rheumatoid arthritis.

25. Stavropoulos PG, Soura E, Kanelleas A, Katsambas A, Antoniou C. Reactive arthritis. J Eur Acad Dermatol Venereol. 2015;29:41524.

26. Fox C, Walker-Bone K. Evolving spectrum of HIV-associated rheumatic syndromes. Best Pract Res Clin Rheumatol. 2015;29: 244-58.

27. Kawahara K, Mukai T, Miyaji Y, Morita Y. Chronic reactive arthritis associated with prostatitis caused by Neisseria meningitidis. BMJ Case Rep. 2018;2018:bcr2017223537.

28. Marwat A, Mehmood H, Hussain A, Khan M, Ullah A, Joshi M. Clostridium difficile colitis leading to reactive arthritis: a rare complication associated with a common disease. J Investig Med High Impact Case Rep. 2018;6:2324709618767689.

29. Birnbaum J, Bartlett JG, Gelber AC. Clostridium difficile: an underrecognized cause of reactive arthritis? Clin Rheumatol. 2008;27: $253-5$.

30•. Tuompo R, Lääveri T, Hannu T, Pakkanen SH, Kirveskari J, Leirisalo-Repo M, et al. Reactive arthritis and other musculoskeletal symptoms associated with acquisition of diarrhoeagenic Escherichia coli (DEC). Ann Rheum Dis. 2020;79:605-11 This is the first prospective study to have employed multivariate analysis in investigating whether reactive musculoskeletal symptoms are associated with acquisition of DEC and determining the incidence of enterogenic ReA among travellers with DEC. The prospective study design allowed the very first evaluation of the incidence of $\mathrm{ReA}$ and various reactive musculoskeletal symptoms among individuals with travel-acquired DEC.

31. Singh Sangha M, Wright ML, Ciurtin C. Strongly positive anti$\mathrm{CCP}$ antibodies in patients with sacroiliitis or reactive arthritis post- $E$. coli infection: a mini case-series based review. Int $\mathrm{J}$ Rheum Dis. 2018;21:315-32.

32. Erre GL, Colombo E, Bibbò S, Dore MP. Reactive arthritis secondary to Hafnia alvei enterocolitis. BMJ Case Rep. 2019;12:e228513.

33. Alamlih L, Abufaied M, Al-Allaf AW. An unusual cause of reactive arthritis with urticarial: a case report. Qatar Med J. 2020;2020: 25 The first case report of on an unusual cause of $\operatorname{ReA}$ and urticaria caused by Blastocystis.

34. Hussein EM, El-Hamshary EM, Omar AS, Mokhtaret AB. Parasitic rheumatism among patients infected with intestinal parasites. Acta Sci Gastrointest Disord. 2019;2(6):19-23.

35. Chun C, Kingsbury DJ. Poststreptococcal reactive arthritis: diagnostic challenges. Perm J. 2019;23:18.304.

36. Sood R, Wali JP, Handa R. Poncet's disease in a north Indian hospital. Trop Dr. 1999;29:33-6.

37. Sharma A, Pinto B, Dogra S, Sharma K, Goyal P, Sagar V, et al. A case series and review of Poncet's disease, and the utility of current diagnostic criteria. Int J Rheum Dis. 2016;19:1010-7.

38•. Shobha V, Desai AM. Poncet's disease diagnostic criteria decodes conundrum: Poncet's vs pseudo Poncet's. Reumatismo. 2019;71: 46-50 The case series demonstrates that the Sharma and Pinto diagnostic criteria performed very well in routine clinical practice. The result of the study can give guidance to clinicians in making the rare diagnosis in relation to a common infection in endemic areas.

39. Calado JOA, Miola AC, Silvares MRC, Marques SA. Disseminated tuberculosis associated with reactive arthritis of Poncet in an immunocompetent patient. An Bras Dermatol. 2020;95:343-6.

40. Endo Y, Kawashiri SY, Koga T, Okamoto M, Tsuji S, Takatani A, et al. Reactive arthritis induced by active extra-articular tuberculosis: a case report. Medicine (Baltimore). 2019;98:e18008.

41. Harjacek M, Ostojic J, Djakovic RO. Juvenile spondyloarthropathies associated with Mycoplasma pneumoniae infection. Clin Rheumatol. 2006;25:470-5.

42. Pilianidis G, Tsinari A, Pandis D, Tsolakidou H, Petridis N. Chronic seronegative spondyloarthropathy following acute Mycoplasma pneumoniae infection in a human leukocyte antigen B27-positive patient: a case report. J Med Case Rep. 2020;14:155.

43. Bajantri B, Venkatram S, Diaz-Fuentes G. Mycoplasma pneumoniae: a potentially severe infection. J Clin Med Res. 2018;10:535-44.

44. Cheung DC, Millman AL, Hamilton RJ. Case: Bacillus CalmetteGuerin (BCG)-induced Reiter syndrome with an attempt at repeat BCG induction. Can Urol Assoc J. 2018;12:E37-9.

45. Freixa M, Úria S, da Silva GN. Reactive arthritis - a rare complication of intravesical BCG instillation. Eur J Case Rep Intern Med. 2020;7:001448.

46. Yoshimura $\mathrm{H}$, Okano $\mathrm{T}$, Inui $\mathrm{K}$, Nakamura $\mathrm{H}$. Ultrasonographic findings in a patient with reactive arthritis induced by intravesical BCG therapy for bladder cancer. J Med Ultrason (2001). 2019;46: $163-5$.

47. Slouma M, Chammakhi M, Dhahri R, Metoui L, Boussetta N, Ajili $\mathrm{F}$, et al. Unusual evolution of reactive arthritis induced by BCG therapy. Therapie. 2019;74:685-8.

48. Redford AH, Trost JR, Sibbitt WL Jr, Fangtham M, Emil NS, Singh S, et al. HLA-B27 spondyloarthritis and spotted fever rickettsiosis: case-based review. Rheumatol Int. 2019;39:1643-50. 
49. Legendre P, Lalande V, Eckert C, Barbut F, Fardet L, Meynard JL, et al. Clostridium difficile associated reactive arthritis: case report and literature review. Anaerobe. 2016;38:76-80

50. Kingsley G, Sieper J. Third International Workshop on Reactive Arthritis. 23-26 September 1995, Berlin, Germany. Report and abstracts. Ann Rheum Dis. 1996;55:564-84.

51. Pacheco-Tena C, Burgos-Vargas R, Vázquez-Mellado J, Cazarín J, Pérez-Díaz JA. A proposal for the classification of patients for clinical and experimental studies on reactive arthritis. J Rheumatol. 1999;26:1338-46.

52. Siala M, Jaulhac B, Gdoura R, Sibilia J, Fourati H, Younes M, et al. Analysis of bacterial DNA in synovial tissue of Tunisian patients with reactive and undifferentiated arthritis by broad-range PCR, cloning and sequencing. Arthritis Res Ther. 2008;10:R40.

53. Siala M, Gdoura R, Fourati H, Rihl M, Jaulhac B, Younes M, et al. Broad-range PCR, cloning and sequencing of the full 16S rRNA gene for detection of bacterial DNA in synovial fluid samples of Tunisian patients with reactive and undifferentiated arthritis. Arthritis Res Ther. 2009;11:R102.

54. Peng SL. Rheumatic manifestations of parasitic diseases. Semin Arthritis Rheum. 2002;31:228-47.

55. Herbette M, Cren JB, Joffres L, Lucas C, Ricard E, Salliot C, et al. Usefulness of polymerase chain reaction for diagnosing Whipple's disease in rheumatology. PLoS One. 2018;13(7):e0200645.

56. Schutzer SE, Body BA, Boyle J, Branson BM, Dattwyler RJ, Fikrig E, et al. Direct diagnostic tests for Lyme disease. Clin Infect Dis. 2019;68:1052-7.

57. Meyer T, Buder S. The laboratory diagnosis of Neisseria gonorrhoeae: current testing and future demands. Pathogens. 2020;9:91.

58. Schaeverbeke T, Bébéar C, Bannwarth B, Bébéar C, Dehais J. Reactive or septic arthritis? Comment on the article by Li et al. Arthritis Rheum. 1997;40(3):592-3.

59. Gaut D, Muir K, Pessegueiro AM. A case of Staphylococcus lugdunensis bacteremia complicated by reactive arthritis. SAGE Open Med Case Rep. 2019;7:2050313X19828249.

60. Madhoun H, Landry K, Baria MR. Induction of HLA-B27associated reactive arthritis after a Wharton's jelly "stem cell" injection: a case report. Am J Phys Med Rehabil. 2020;99:e142-5. https://doi.org/10.1097/PHM.0000000000001418.

61. Horino T, Inotani S, Matsumoto T, Ichii O, Terada Y. Reactive arthritis caused by Rothia mucilaginosa in an elderly diabetic patient. J Clin Rheumatol. 2019;26:e303-4. https://doi.org/10.1097/ RHU.0000000000001157.

62. Ono K, Kishimoto M, Shimasaki T, Uchida H, Kurai D, Deshpande GA, et al. Reactive arthritis after COVID-19 infection. RMD Open. 2020;6:e001350. https://doi.org/10.1136/rmdopen-2020-001350.

63. Danssaert Z, Raum G, Hemtasilpa S. Reactive arthritis in a 37-yearold female with SARS-CoV2 infection. Cureus. 2020;12(8):e9698.

64. Yokogawa N, Minematsu N, Katano H, Suzuki T. Case of acute arthritis following SARS-CoV-2 infection. Ann Rheum Dis. 2020: annrheumdis-2020-218281. https://doi.org/10.1136/annrheumdis2020-218281.

65. Liew IY, Mak TM, Cui L, Vasoo S, Lim XR. A case of reactive arthritis secondary to coronavirus disease 2019 infection. J Clin Rheumatol. 2020 Sep;26(6):233.

66. De Stefano L, Rossi S, Montecucco C, Bugatti S. Transient monoarthritis and psoriatic skin lesions following COVID-19. Ann Rheum Dis. 2020:annrheumdis-2020-218520. https://doi. org/10.1136/annrheumdis-2020-218520.

67. Schenker HM, Hagen M, Simon D, Schett G, Manger B. Reactive arthritis and cutaneous vasculitis after SARS-CoV-2 infection. Rheumatology (Oxford). 2020 :keaa689. https://doi.org/10.1093/ rheumatology/keaa689.

68. Mukarram IG, Mukarram MS, Ishaq K, Riaz SU. Post COVID-19 reactive arthritis: an emerging existence in the spectrum of musculoskeletal complications of SARS-CoV-2 infection. J Clin Stud Med Case Rep. 2020;7:0101.

69. Jali I. Reactive arthritis after COVID-19 Infection. Cureus. 2020;12:e11761.

70••. Wendling D, Verhoeven F, Chouk M, Prati C. Can SARS-CoV-2 trigger reactive arthritis? Joint Bone Spine. 2020;27:105086. https://doi.org/10.1016/j.jbspin.2020.105086 The overview discusses case reports of acute arthritis or dactylitis associated with SARS-CoV-2 infection, some of which may be suggestive of reactive arthritis. Potential hypothetic mechanisms involved in the pathogenesis of the arthritis are introduced.

71. Graef ER, Liew JW, Kim AH, Sparks JA. Response to: 'Case series of acute arthritis in COVID-19 admission' by López-González et al. Ann Rheum Dis. 2020:annrheumdis-2020-217989. https://doi.org/ 10.1136/annrheumdis-2020-217989.

72. Lopez-Gonzalez M, Peral-Garrido ML, Calabuig I. A case series of acute arthritis during COVID-19 admission. Ann Rheum Dis. 2020. https://doi.org/10.1136/annrheumdis-2020-217914.

73. Robinson PC, Kempe S, Tebbutt I, Roberts L. Epidemiology of inpatient gout in Australia and New Zealand: temporal trends, comorbidities and gout flare site. Int J Rheum Dis. 2017;20:779-84.

74. Schmitt SK. Reactive arthritis. Infect Dis Clin N Am. 2017;31:26577.

75. Carter JD, Hudson AP. Recent advances and future directions in understanding and treating Chlamydia-induced reactive arthritis. Expert Rev Clin Immunol. 2017;13:197-206.

76. Dumusc A, Hugle T. L'arthrite réactionnelle. Rev Med Suisse. 2018;14:534-7.

77. Sharip A, Kunz J. Understanding the pathogenesis of spondyloarthritis. Biomolecules. 2020;10:1461. https://doi.org/ 10.3390/biom10101461.

78. Mousave S, Bereswill S, Heimesaat MM. Novel clinical Campylobacter jejuni infection models based on sensitization of mice to lipooligosaccharide, a major bacterial factor triggering innate immune responses in human campylobacteriosis. Microorganisms. 2020;8:482. https://doi.org/10.3390/microorganisms8040482.

79. Verma A, Sharda S, Rathi B, Somvanshi V, Pandey BD. Elucidating potential molecular signatures through host-microbe interactions for reactive arthritis and inflammatory bowel disease using combinatorial approach. Sci Rep. 2020;10:15131. https://doi. org/10.1038/s41598-020-71674-8.

80. Iglesias-Gamarra A, Mendez EA, Cuellar ML, Ponce de Leon JH, Jimenez C, Canas C, et al. Poststreptococcal reactive arthritis in adults: long-term follow-up. Am J Med Sci. 2001;321:173-7.

81. Mackie SL, Keat A. Poststreptococcal reactive arthritis: what is it and how do we know it. Rheumatology. 2004;43:949-54.

82. Vega-Villanueva KI, Espinoza LR. Expanding the spectrum of spondyloarthritis $(\mathrm{SpA})$, post-streptococcal reactive arthritis(PSRA) related psoriatic spondyloarthritis (PSpA). Clin Rheumatol. 2019;38:2363-5.

83. Daga A, Dahan S, Shemer A, Langevitz P, Hellou T, Davidson T, et al. Acute onset of psoriatic spondyloarthritis as a new manifestation of post-streptococcal reactive arthritis: a case series. Clin Rhematol. 2019;38:2367-72.

84. Gérard HC, Wang Z, Whittum-Hudson JA, Bardin T, Schumacher HR, Hudson AP. Cytokine and chemokine mRNA produced in synovial tissue chronically infected with $C$ trachomatis and Chlamydia pneumoniae. J Rheumatol. 2002;29:1827-35.

85. Gérard HC, Schumacher HR, El-Gabalawy H, Goldbach-Mansky R, Hudson AP. Chlamydia pneumoniae infecting the human synovium are viable and metabolically active. Microb Pathog. 2000;29:17-24.

86. Ibtissam B, Abdelgahni KB, Rostom S, Amine B, Laatar A, Bahiri R. Reactive arthritis: update. Curr Clin Microbiol Rep. 2020;26:p19. https://doi.org/10.1007/s40588-020-00152-6. 
87. Marker-Hermann E. Reactive arthritis - a disease almost forgotten? (in German). Dtsch Med Wochenschr. 2020;145:1786-0.

88. Finckh A. Reactive arthritis - inflammation or true infection? (in French). Rev Med Suisse. 2016;12:503-6.

89. Saricaoglu EM, Hasanoglu I, Guner R. The first reactive arthritis case associated with COVID-19. J Med Virol. 2020;fragata 11. https://doi.org/10.1002/jmv.26296.

90. Fragata I, Mourao AF. Coronavirus disease 19 (COVID-19) complicated with post-viral arthritis. Acta Rheumatol Port. 2020;45: 278-80.
91. Venigalla SSK, Premakumar S, Janakiraman V. A possible role for autoimmunity through molecular mimicry in alphavirus mediated arthritis. Sci Rep. 2020;10:938. https://doi.org/10.1038/s41598019-55730-6.

Publisher's Note Springer Nature remains neutral with regard to jurisdictional claims in published maps and institutional affiliations. 